\title{
UMA VISÃO DA RELAÇÃO DO TELETRABALHO E DA TELECONSULTORIA NO ÂMBITO DA TELESSAÚDE NO ESTADO DO RIO GRANDE DO NORTE
}

\section{Janaína Luana Rodrigues da Silva}

Bacharel em Secretariado Executivo, Especialista em Teletrabalho e Telessaúde. Pósgraduanda pela Universidade Federal do Rio Grande do Norte

E-Mail: janaina@telessaude.lais.huol.ufrn.br.

\section{Francis Solange Tourinho}

Doutora em Enfermagem, Professora do Departamento de Enfermagem da Universidade Federal do Rio Grande do Norte. E-Mail: francistourinho@gmail.com.

\section{Daniele Montenegro da Silva Barros}

Mestranda no Programa de Pós-graduação em Engenharia Elétrica e Computação da Universidade Federal do Rio Grande do Norte. E-Mail: monte.daniele@gmail.com.

\section{José Diniz Júnior}

Doutor em Medicina, Professor do Departamento de Cirurgia da Universidade Federal do Rio Grande do Norte. E-Mail: diniz@ufrnet.br.

\section{Lyane Ramalho Cortez}

Médica do Hospital Universitário Onofre Lopes da Universidade Federal do Rio Grande do Norte. E-Mail: lyane@superig.com.br.

\section{UMA VISÃO DA RELAÇ̃̃O DO TELETRABALHO E DA TELECONSULTORIA NO ÂMBITO DA TELESSAÚDE NO ESTADO DO RIO GRANDE DO NORTE}

\section{ARTIGO DE OPINIÃO}

"É fato inegável que o teletrabalho vem se difundindo não só no Brasil, mas em diversas partes do mundo, principalmente em razão da utilização de recursos inovadores em telecomunicações e tecnologias da informação e da busca da gestão sustentável. Desta forma, profissionais, técnicos e trabalhadores em geral, instalados em suas casas, em escritórios virtuais ou em outros espaços alternativos, dispondo de equipamentos que os mantêm conectados com a organização ou com uma rede de trabalhadores com os quais cooperam, podem processar informações (tarefas burocráticas e administrativas normalmente feitas nos escritórios da organização), produzir idéias, desenvolver pesquisas e demais atividades rotineiras e intelectuais" (Mello e Ferreira, 2012). 
No âmbito da saúde, o Ministério da Saúde em 2005 criou o Programa Telessaúde Brasil, que hoje é conhecido por Telessaúde Brasil Redes. Esse programa representa uma articulação importante com a estratégia em saúde da família essencialmente na atenção básica à saúde, pois permite que equipes de saúde possam ter acesso a médicos da família a distância e também possam estar incluídos no processo permanente de educação, conhecido como Teleeducação.

Especificamente no que tange as teleconsultorias, segundo a Portaria $\mathrm{N}^{\mathrm{o}} 2.546$, de 27 de Outubro de 2011 do Ministério da Saúde, Art. 20:

[...] O Telessaúde Brasil Redes fornecerá aos profissionais e trabalhadores das Redes de Atenção à Saúde no SUS os seguintes serviços:

I - Teleconsultoria: consulta registrada e realizada entre trabalhadores, profissionais e gestores da área de saúde, por meio de instrumentos de telecomunicação bidirecional, com o fim de esclarecer dúvidas sobre procedimentos clínicos, ações de saúde e questões relativas ao processo de trabalho [...]

Parágrafo único. As Teleconsultorias, os Telediagnósticos, as Segundas Opiniões Formativas e as ações de Tele-educação demandadas pelos profissionais de saúde do SUS poderão ser elaborados e respondidos por Teleconsultores a partir de qualquer Núcleo de Telessaúde Técnico-Científico ou Ponto de Telessaúde.

Como pode ser observado na descrição da portaria do Ministério da Saúde, existe uma forte caracterização entre o teletrabalho e a teleconsultoria, uma vez que o processo de teleconsultoria efetivamente se apóia no uso das tecnologias da informação e comunicação para desenvolver essa atividade. Dessa forma, trata-se de uma assistência em saúde na modalidade à distância, cujo propósito é esclarecer dúvidas sobre procedimentos clínicos, ações de saúde e questões relativas ao processo de trabalho.

No contexto da saúde do Rio Grande do Norte é importante destacar que em 2011 iniciouse o processo de implantação do Núcleo de Telessaúde, conduzido e gerenciado pela Universidade Federal do Rio Grande Norte. Esse processo vem sendo conduzido até hoje, uma vez que o projeto ainda está sendo implantado em alguns municípios. É importante destacar que o processo de teleconsultas teve início em março de 2012, pois na fase inicial do projeto a equipe optou por desenvolver suas próprias ferramentas de software para a execução das tarefas do projeto.

O maior desafio encontrado foi a logística para implantação dos pontos, haja vista a falta de conectividade e principalmente pelo desconhecimento do Programa Telessaúde no Estado. Outra dificuldade encontrada, diz respeito ao período de mudança dos gestores municipais decorrente do interstício de mandatos. Outro desafio importante trata dos aspectos técnicos, uma vez que os trabalhadores de saúde do Estado do Rio Grande do Norte não estavam capacitados para atuar com ferramentas de teletrabalho, no sentido de demandar, realizar e responder teleconsultorias, sendo esse um binômio importante para o Telessaúde-RN. 
Neste ínterim, o Ministério da Saúde lançou o PROVAB, (Programa de Valorização do Profissional da Atenção Básica) que no ano de 2013 inseriu 174 médicos somente no Estado do Rio Grande Norte. Com isso, o Telessaúde-RN passou a assumir um papel importante de qualificação desses médicos nas ferramentas de Telessaúde, ou seja, em sua plataforma de teleconsultoria, bem como, no Portal de Telessaúde. Por se tratar de um público de médicos mais jovem, os quais já estão inseridos no contexto das tecnologias da informação e comunicação, o Telessaúde e suas ferramentas tiveram uma boa receptividade por parte desses profissionais. Esse é um aspecto que deverá fortalecer os programas (Telessaúde e PROVAB) no Estado do RN, devido a sua forte articulação com a atenção básica e integração entre os Programas.

Atualmente 16 municípios do RN estão com pontos de Telessaúde, dos quais, apenas quatro tem médicos do PROVAB atuando. Todavia, já está planejado para a segunda fase do Projeto Telessaúde a cobertura de $100 \%$ dos municípios que tenham aderido ao PROVAB. Esse fator irá impulsionar de sobremaneira as teleconsultorias, que atualmente funcionam somente por meio da Telepediatria no RN.

Há uma estimativa de que, com as demanda do PROVAB para o Telessaúde, as teleconsultorias ultrapassem, entre os anos de 2013 e 2015, o quantitativo de mais de 17000. Essa previsão demandará pesquisas relacionadas a questões bioéticas, tanto pelos aspectos legais nas relações de teletrabalho em telessaúde, quanto pelas questões do atendimento remoto a pacientes. Tais pesquisas deverão nortear o processo de regulação do teletrabalhador da saúde (profissional de saúde). Deste modo, criando e recriando novas relações de trabalho na Telessaúde, bem como, no processo de atendimento de pacientes na modalidade à distância - isso é o que se espera para o futuro. É importante destacar que, de certa forma, já existe um esforço nessa direção tanto do Ministério da Saúde, quanto das Universidades e demais entidades participantes.

Por fim, um aspecto relevante que deve ser observado decorrente da utilização da telessaúde, diz respeito a avaliação de desempenho de seus núcleos, ou seja, investimento versus retorno na melhoria da qualidade do atendimento aos pacientes. Desta forma, surgem questões importantes como exemplo, dialogar sobre o impacto da telessaúde na atenção básica, nas questões epidemiológicas, na saúde do idoso, na redução da mortalidade infantil, dentre outras questões pertinentes a estratégia da saúde da família. Neste contexto, a avaliação desses resultados deverão ser utilizados para balizar os indicadores da telessaúde no Brasil. Esse fator, certamente irá criar importantes áreas de estudos e pesquisas nas relações dos teletrabalhadores da saúde, ou seja, o teleconsultor ou teleregulador, bem como a qualidade do atendimento prestado aos pacientes e os impactos gerados no sistema de saúde brasileiro.

\section{REFERÊNCIAS BIBLIOGRÁFICAS}

1. Mello AAA, Ferreira WT. Normatização, regulação e legislação para o teletrabalho. In: Mathias I, Monteiro A, organizadores. Gold book - Inovação tecnológica em educação e saúde. Rio de Janeiro, RJ: EdUERJ, 2012; p. 712-20. Disponível em: http://www.telessaude.uerj.br/resource/goldbook/pdf/40.pdf.

2. PORTARIA $\mathrm{N}^{\mathrm{o}}$ 2.546, DE 27 DE OUTUBRO DE 2011. Disponível em: http://bvsms.saude.gov.br/bvs/saudelegis/gm/2011/prt2546_27_10_2011.html 